\title{
Complement Depletion and Persistent Hemodynamic-Hematologic Responses in Protamine-Heparin Reactions
}

\author{
Thomas W. Wakefield, M.D., Gerd O. Till, M.D., Bengt Lindblad, M.D., Ph.D., \\ Nick SaENZ, M.D., and James C. STANLEY, M.D.
}

Section of Vascular Surgery, Department of Surgery, and Department of Pathology, University of Michigan

Medical School, Ann Arbor, Michigan 48109-0331

Submitted for publication April 7, 1987

\begin{abstract}
Hypotension, bradycardia, pulmonary artery hypertension, neutropenia, and thrombocytopenia have been suspected to be due to complement activation following protamine reversal of heparin. This investigation examined these phenomena in complement-depleted animals. Eight dogs received intraperitoneal naja n. naja cobra venom factor (CVF), $20 \mathrm{U} / \mathrm{kg}, 48$ and $24 \mathrm{hr}$ prior to anticoagulation with sodium heparin, $150 \mathrm{IU} / \mathrm{kg}$, and reversal $30 \mathrm{~min}$ later with protamine sulfate, $1.5 \mathrm{mg} / \mathrm{kg}$. Decomplementation was confirmed in all dogs. Systemic blood pressure (BP), pulse (HR), pulmonary artery systolic and diastolic pressures, (PAS, PAD), cardiac output (CO), platelet count (PTC), and white blood count (WBC) with differential were monitored. The maximal mean changes for the entire group were BP, $-43 \mathrm{~mm} \mathrm{Hg}$; $\mathrm{HR},-16$; PAS, $+6 \mathrm{~mm} \mathrm{Hg}$ PAD, $+3 \mathrm{~mm} \mathrm{Hg}$; CO, $-27 \%$; PTC, $-49 \%$; and WBC, $-48 \%$. These hemodynamic and hematologic responses, occurring in the face of CVF-induced decomplementation, support the conclusion that complement components $\mathrm{C} 3$ and $\mathrm{C} 5-\mathrm{C} 9$ are not influential factors contributing to these protamine-heparin-induced events. $\odot 1988$ Academic Press, Inc.
\end{abstract}

Protamine sulfate is a useful agent for the reversal of the anticoagulant effect of sodium heparin. However, in both animals and patients, this drug may cause a number of undesirable hemodynamic and hematologic adverse responses, including hypotension, bradycardia, pulmonary artery hypertension, thrombocytopenia, and neutropenia [1-4]. Complement activation has been suspected to be the cause of these responses, although a direct relationship between hematologic changes and complement activation after protamine administration has not been observed in prior experiments undertaken by the authors [2, 3]. The purpose of this investigation was to produce a state of complement deficiency in animals utilizing cobra venom factor (CVF) and to quantitate subsequent responses to protamine reversal of heparin anticoagulation.

\section{MATERIALS AND METHODS}

Eight adult mongrel dogs (mean weight, 13 $\mathrm{kg}$ ) were treated with cobra venom factor from the naja $n$. naja cobra 48 and $24 \mathrm{hr}$ prior to the experimental study. The venom was given intraperitoneally for a total dose of $40 \mathrm{U} / \mathrm{kg}(20 \mathrm{U} / \mathrm{kg}$ with each administration). CVF was isolated from crude lyophilized cobra venom by ion-exchange chromatography and gel filtration [5].

The dogs were anesthetized with sodium pentobarbital ( $30 \mathrm{mg} / \mathrm{kg}$ intravenous) and mechanically ventilated. Anesthesia was maintained with supplemental sodium pentobarbital. Hydration was assured by administration of lactated Ringers solution, 20 $\mathrm{cc} / \mathrm{kg} / \mathrm{hr}$. All animals had an arterial catheter placed in the right femoral artery, a SwanGanz catheter placed in the pulmonary artery by way of the right femoral vein, and a venous catheter inserted in the left femoral vein. Hemodynamic measurements included mean systemic blood pressure (BP), pulse (HR), pulmonary artery systolic pressure (PAS), pulmonary artery diastolic pressure (PAD), and cardiac output (CO) using thermodilution technique. Hematologic 
measurements included platelet count (PTC), complete blood count (CBC) with differential count, total hemolytic complement $\left(\mathrm{CH}_{50}\right)$ values, and crossed immunoelectrophoresis for monitoring of complement activation.

All animals were heparinized with sodium heparin (150 IU $/ \mathrm{kg}$, intravenous) and 30 min later the heparin was reversed with protamine sulfate $(1.5 \mathrm{mg} / \mathrm{kg}$, infused intravenously over a 10 -sec period). These are standard doses administered clinically at our medical center. The rapid protamine infusion was chosen to magnify hemodynamic responses. Hemodynamic measurements including BP, HR, PAS, and PAD were monitored continuously. $\mathrm{CO}, \mathrm{PTC}$, and $\mathrm{CBC}$ were monitored at baseline, $3 \mathrm{~min}$ after heparin administration, $3 \mathrm{~min}$ prior to protamine reversal, and at $30 \mathrm{sec}, 1,3,5,10$, and $30 \mathrm{~min}$ following completion of the protamine reversal.

Thrombin clotting times revealed full anticoagulation in all animals after heparin administration and complete reversal with administration of protamine sulfate. Hematologic assessments were also made before and after each administration of CVF.

Complement depletion was documented by assaying plasma samples for total hemolytic complement activity ( $\mathrm{CH}_{50}$ units), employing a standard hemolysis test [6]. Plasma C3 levels were determined by crossed immunoelectrophoresis procedures using a specific antibody against canine $\mathrm{C} 3$. Since the height of the $\mathrm{C} 3$ peak in the gel slab relates directly to the amounts of $\mathrm{C} 3$ present in plasma, percentage changes in $\mathrm{C} 3$ concentrations were easily calculated. Data analyses included calculation of sample means with standard deviations, and comparisons using a paired $t$ test. Animal care complied with the Principles of Laboratory Animal Care and the Guide for the Care and Use of Laboratory Animals (NIH Publication No. 80-23, revised 1976).

\section{RESULTS}

Protamine reversal of heparin produced a maximal fall in BP of $43 \pm 24 \mathrm{~mm} \mathrm{Hg}$ at 150 sec with a persistent decline of $9 \pm 16 \mathrm{~mm}$ $\mathrm{Hg}$ at $30 \mathrm{~min}$ (Fig. 1). Statistically significant differences from baseline BP were noted from 75 to $180 \mathrm{sec}$ after reversal. Intercstingly, two dogs showed only minimal hypotension with BP decreases of 10 and $12 \mathrm{~mm}$ $\mathrm{Hg}$, respectively. The HR dropped $15 \pm 18$ at $135 \mathrm{sec}$ and $16 \pm 14$ at $5 \mathrm{~min}$ (Fig. 2). Significant differences from baseline HR were found at $135 \mathrm{sec}$, as well as at 5 and $10 \mathrm{~min}$.

Elevations of both systolic and diastolic pulmonary artery pressure occurred. The maximal PAS rise was $6 \pm 9 \mathrm{~mm} \mathrm{Hg}$ at $60 \mathrm{sec}$ after protamine administration, and the maximal PAD rise was $3 \pm 6 \mathrm{~mm} \mathrm{Hg}$ at this same time interval. These values were not statistically different from baseline pressures (Fig. 3). Finally, CO declined $27 \%$ from initial baseline values at $180 \mathrm{sec}$ after protamine administration, although there was an initial rise at $30 \mathrm{sec}$ (Fig. 4).

Hematologic changes were more marked. PTC fell $49 \%$ from initial counts at $60 \mathrm{sec}$ after protamine administration and remained $30 \%$ below baseline at $30 \mathrm{~min}$ (Fig. 5). Significant PTC differences occurred at all time periods. Similarly, white blood cell counts fell $48 \%$ from baseline at $60 \mathrm{sec}$ following protamine administration (Fig. 6). Full recovery of the latter was noted by 5

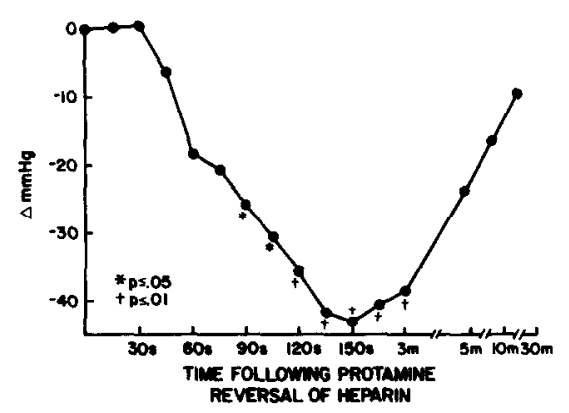

FIG. 1. Mean systemic arterial blood pressure change after protamine reversal of heparin. 


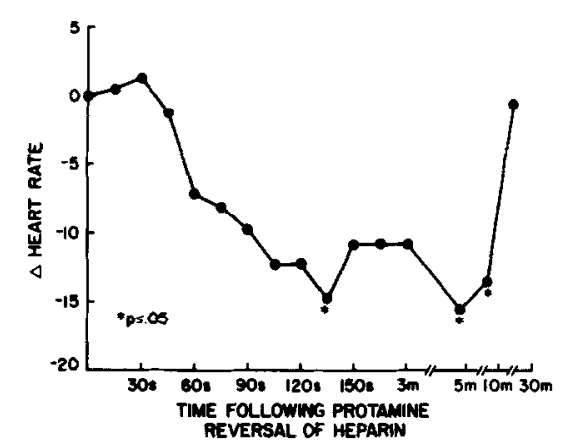

FiG. 2. Pulse change after protamine reversal of heparin.

min. There was a slight decline in the percentage of granulocytes, from 47 to $38 \%$ at $30 \mathrm{sec}$ after protamine reversal. The percentage of lymphocytes rose initially from 36 to $47 \%$ at $30 \mathrm{sec}$, and declined to $30 \%$ at 5,10 , and $30 \mathrm{~min}$ after the protamine reversal. Eosinophils accounted for $5 \%$ of the white cells initially, a percentage that increased to $12 \%$ at $60 \mathrm{sec}$ following protamine reversal. Monocyte, basophil, and stab analysis did not reveal any significant changes, probably reflecting their initial low levels of 4,2 , and $1 \%$, respectively.

Baseline PTC before the first CVF administration was $284,000 \pm 98,000$. PTC just prior to protamine reversal $48 \mathrm{hr}$ later was $251,000 \pm 81,000$, representing a slight decrease of $12 \%$. The baseline white blood cell count before the first CVF administration was $24,000 \pm 19,000$ and $48 \mathrm{hr}$ later it had

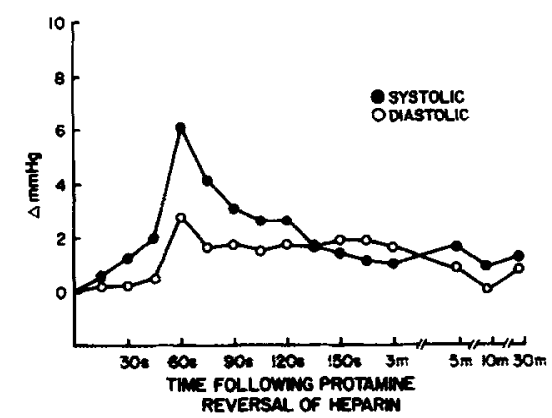

Fig. 3. Pulmonary artery blood pressure change (systolic, diastolic) after protamine reversal of heparin.

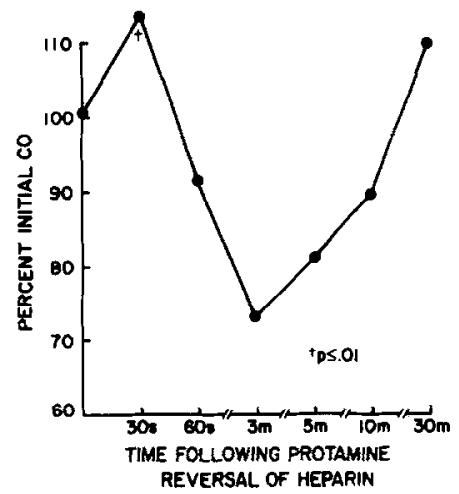

FIG. 4. Cardiac output change after protamine reversal of heparin.

fallen to $5000 \pm 3900$, a decrease of $79 \%$. Interestingly, the white blood cell count 24 $\mathrm{hr}$ after the first CVF administration had increased $31 \%$ to $31,400 \pm 8900$.

Total hemolytic complement activity in plasma was 95.3 units before CVF treatment, but only 10 units after the second CVF administration. At the same time, there was an $83 \pm 3 \%$ reduction in plasma $C 3$ levels compared to pretreatment values.

\section{DISCUSSION}

Complement activation has been suggested as a cause of the adverse hemodynamic and hematologic effects of protamine sulfate [7-13]. It has been known for more than a decade that protamine, when added to

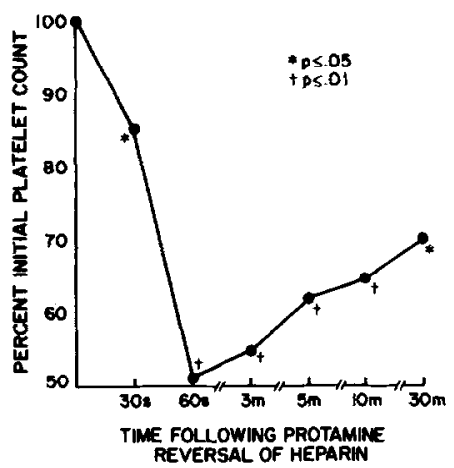

FIG. 5. Platelet count change after protamine reversal of heparin. 


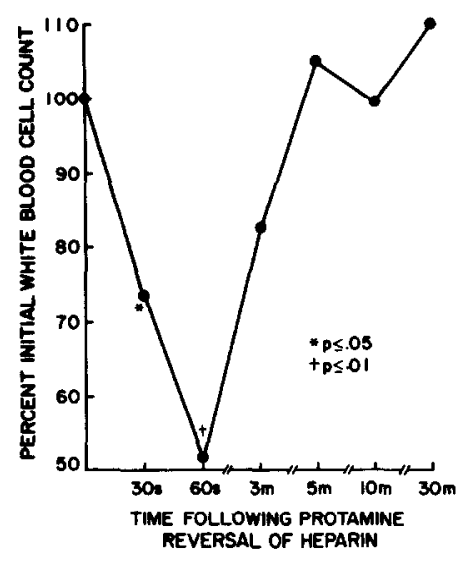

FIG. 6. White blood cell count change after protamine reversal of heparin.

acute phase serum, consumed the complement cascade components $\mathrm{C} 1, \mathrm{C} 4$, and $\mathrm{C} 2$, with little consumption of $\mathrm{C} 3-\mathrm{C} 9$, in a reaction that was dependent on time, temperature, $\mathrm{pH}$, and salt concentration, including the presence of calcium ions [9]. This reaction occurred even in the absence of heparin, as well as in normal sera with high doses of protamine. C-reactive protein appears to be the essential component in acute phase serum, which acts with protamine to facilitate this response that has been postulated to begin at the level of C1q.

Combinations of heparin and protamine, at levels below those causing complement activation if either substance is given separately, deplete total hemolytic complement in vitro [10]. Heparin was found to be approximately 20 times more anticomplementary in the presence of protamine sulfate, and protamine was 5-10 times more anticomplementary in the presence of sodium heparin [10]. Heparin, alone, minimally lowered $\mathrm{C} 1$ and $\mathrm{C} 3-\mathrm{C} 9$ levels, but augmented $\mathrm{C} 4$ and $\mathrm{C} 2$ activity, an effect thought to be due to heparin's action on antithrombin III. Protamine, alone had little effect on complement activation in the aforementioned study. However, heparin plus protamine depleted total hemolytic complement in the fashion of an antibody-antigen complex with classical pathway activation beginning at the level of $\mathrm{Cl}$.

Earlier in vitro studies were followed by in vivo experiments using rabbits in which gencration of C5a was implied by existance of a transient granulocytopenia produced by heparin-protamine interaction [11]. This response was also noted to occur following protamine administration alone in animals having elevated $\mathrm{C}$-reactive protein levels, albeit not to a statistically significant degree. Depletion of complement factors with CVF completely abolished the granulocytopenic response. This indirectly supported the contention that complement, up to and including $C 5$, could be activated by protamine.

Humans undergoing cardiopulmonary bypass exhibited elevated C3a and C4a levels after protamine reversal of heparin, implicating classical pathway activation [12]. These elevations were distinct from those occurring in the cardiopulmonary bypass circuit itself. It was postulated that complement activation, pulmonary sequestration of leukocytes, lysosomal enzyme release, superoxide generation, histamine release from mast cells, and finally increased capillary permeability occurred in response to protamine reversal of heparin. However, it should be noted that the 100 patients in this study did not exhibit reversal hypotension and thus correlations of hemodynamic data to complement values were not possible. In addition, the measurements in the aforementioned study were obtained $10 \mathrm{~min}$ after protamine reversal, a time beyond that when the adverse responses have been documented to occur in peripheral vascular surgery patients with protamine reversal of heparin [2]. Similar findings have been noted by Kirklin and his colleagues [13].

In contrast to these two former studies, that both suggest complement activation associated with heparin-protamine interactions, is a third report on humans undergoing cardiopulmonary bypass [14]. In this study no consumption of complement, particularly $\mathrm{C} 3$ and $\mathrm{C} 4$, could be documented 
following protamine reversal of heparin anticoagulation. In this regard, we were unable to document activation of total hemolytic complement with protamine reversal of heparin activity in an earlier canine study [3], and in a patient study no correlation existed between hemodynamic parameters and $\mathrm{C} 3 \mathrm{a}$ generation [2].

In the present investigation, we chose to study dogs depleted of complement factors by treatment with CVF in an attempt to resolve the controversy surrounding this topic. CVF is a $144,000 \mathrm{Da}$ protein that works with a cofactor (factor B of the alternative complement pathway) to causc complement activation $[15,16]$. CVF interacts with factor $B$ in a reversible, $\mathrm{Mg}^{2+}$-dependent complex, in order to be cleaved by another cofactor of the alternative pathway (factor D). From this interaction, factor $B$ is cleaved to a smaller fragment $(\mathrm{Ba})$ which is released and a larger fragment $(\mathrm{Bb})$ which remains bound to the CVF. This binding is important for $\mathrm{C} 3$ cleavage and perpetuation of the alternative pathway. Thus, by this means CVF leads to massive activation of the alternative complement cascade and decomplementation for both the classical and alternative pathways from C3 to C9. The low complement levels achieved by CVF may remain reduced for as long as 5 days $[15,17]$. Decomplementation was complete in all animals of the current investigation.

We have previously studied the hemodynamic and hematologic responses in dogs to protamine reversal of heparin using standard doses as used in the current study $[1,3,18]$. In complement-intact animals, the blood pressure typically dropped $40 \mathrm{~mm} \mathrm{Hg}$ at 75 and $120 \mathrm{sec}$ after reversal along with profound bradycardia of -19 at 90 to $105 \mathrm{sec}$ postreversal. Pulmonary artery hypertension occurred some $90 \mathrm{sec}$ after reversal up to +9 $\mathrm{mm} \mathrm{Hg}$ PAS, and cardiac output diminished by $30 \%$ at $60 \mathrm{sec}$ postreversal. Platelet count typically fell $75 \%$, while white blood cell count dropped $60 \%$ at $60 \mathrm{sec}$ after reversal. Finally, only a $7 \%$ activation of $\mathrm{CH}_{50}$ was noted in animals $30 \mathrm{sec}$ and 5 min after reversal.

Certain differences were apparent when comparing the results of this study to our earlier work. First, the typical two-phase hypotensive response as noted previously did not occur [3]. Second, pulmonary artery pressure elevations occurred earlier than would have been expected and were slightly less than those reported previously [3]. Third, although neutropenia did develop, the expected granulocytopenia was not observed [3]. Finally, the magnitude of the thrombocytopenia was slightly less than predicted. [3]. A few comments regarding our understanding of the events surrounding the responses usually accompanying heparinprotamine reactions deserve comment.

As mentioned, protamine-induced hypotension is typically a two-phase response after a 10-sec rapid bolus of protamine, phase one being maximal at $75 \mathrm{sec}$ and phase two at $120 \mathrm{sec}$. Bradycardia and pulmonary artery hypertension are most marked 90 and $105 \mathrm{sec}$ after reversal. Each phase may be mediated by different mechanisms. The first phase seems most likely to be due to a direct toxic effect of protamine on vessels or their cell membranes. This effect leads to vasodilation with a corresponding decrease in total peripheral resistance. Although thrombocytopenia does develop during this first phase, thrombocytopenic dogs still demonstrate early hypotension [19]. On the other hand, platelet aggregation and release of vasoactive substances most probably are responsible for phase two reactions, causing pulmonary artery hypertension, bradycardia, and further hypotension $[3,20]$. Thrombocytopenic dogs do not develop bradycardia and pulmonary artery hypertension [19]. The second phase may be thrombin dependent in that platelets subjected to protamine are inhibited in their aggregation to thrombin but not ADP $[19,21,22]$. In addition, we have demonstrated that pulmonary accumulation of platelets can be completely blocked by protamine pretreatment in the dog [18]. 
Complement activation in animals and humans following protamine administration appears to be a secondary event rather than a cause of major hemodynamic and hematologic changes. That adverse hemodynamic and hematologic responses to protamine occur in dogs with documented decomplementation supports this contention. Although $\mathrm{C} 1, \mathrm{C} 4$, or $\mathrm{C} 2$ components of the cascade could contribute to the adverse responses, inasmuch as these components are not inhibited by the CVF, it is unlikely that one of them is responsible for all the observed reactions without further generation of activated $\mathrm{C} 3, \mathrm{C} 5$, and the rest of the cascade. However, $\mathrm{C} 2$ activation is known to generate a kinin-like moiety, and $\mathrm{C} 4 \mathrm{a}$ anaphylatoxin exists, both of which can cause vasodilation and increased capillary permeability [23]. The influence of these specific component factors in heparin-protamine reactions must still be investigated. Nevertheless, this study documents that inhibition of complement was not protective against the adverse reactions noted with protamine reversal of heparin activity although the magnitude of some of the responses was slightly less than previously reported from our laboratory in studies of this canine model [3].

\section{ACKNOWLEDGMENT}

The authors wish to acknowledge the Upjohn Company (Kalamazoo, MI) for their support of this investigation.

\section{REFERENCES}

1. Wakefield, T. W., Whitehouse, W. M., Jr., and Stanley, J. C. Depressed cardiovascular function and altered platelet kinetics following protamine sulfate reversal of heparin activity. J. Vasc. Surg. 1 : $346,1984$.

2. Wakefield, T. W., Hantler, C. B., Lindblad, B., Whitehouse, W. M., Jr., and Stanley, J. C. Protamine pretreatment attenuation of hemodynamic and hematologic effects of heparin-protamine interaction: A prospective randomized study in human beings undergoing aortic reconstructive surgery. J. Vasc. Surg. 3: 885, 1986.
3. Wakefield, T. W., Lindblad, B., Whitehouse, W. M., Jr., Hantler, C. B., and Stanley, J. C. Attenuation of hemodynamic and hematologic effects of heparinprotamine sulfate interaction after aortic reconstruction in a canine model. Surgery 100: 45 , 1986.

4. Horrow, J. C. Protamine: A review of its toxicity. Anesth. Analg. 64: 348, 1985.

5. Ballow, M., and Cochrane, C. G. Two anticomplementary factors in cobra venom: Hemolysis of guinea pig erythrocytes by one of them. J. Immunol. 103: 994, 1969.

6. Mayer, M. M. Complement and complement fixation. In Kabat and Mayer, (Eds.), Experimental Immunochemistry. Springfield, IL: Thomas, 1961. Pp. 133-240.

7. Kirkland, J. K. in discussion of Shapira, N., Schaff, H. V., Piehler, J. M., White, R. D., Sill, J. C., and Pluth, J. R. Cardiovascular effects of protamine sulfate in man. J. Thorac. Cardiovasc. Surg. 84: 505, 1982.

8. White, J. V. Complement activation during cardiopulmonary bypass. N. Engl. J. Med. 305: 51, 1981.

9. Siegel, J., Rent, R., and Gewurz, H. Interactions of C-reactive protein with the complement system. 1 . Protamine-induced consumption of complement in acute phase sera. J. Exp. Med. 140: 631, 1974.

10. Rent, R., Ertel, N., Eisenstein, R., and Gewurz, H. Complement activation hy interaction of polyanions and polycations. I. Heparin-protamine induced consumption of complement. J. Immunol. 114: 120, 1975.

11. Fehr, J., and Rohr, H. In vivo complement activation of polyanion-polycation complexes: Evidence that $\mathrm{C5a}$ is generated intravascularly during heparin-protamine interaction. Clin. Immunol. Immunopathol. 29: 7, 1983.

12. Cavarocchi, N. C., Schaff, II. V., Orszulak, T. A., Homburger, H. A., Schnell, W. A., and Pluth, J. R. Evidence for complement activation by protamineheparin interaction after cardiopulmonary bypass. Surgery 98: 525, 1985.

13. Kirklin, J. K., Chenoweth, D. E., Naftel, D. C., Blackstone, E. H., Kirklin, J. W., Bitran, D. D., Curd, J. G., Reves, J. G., and Samuelson, P. N. Effects of protamine administration after cardiopulmonary bypass on complement, blood elements and the hemodynamic state. Ann. Thorac. Surg. 41: 193, 1986.

14. Chiu, R. C. J., and Samson, R. Complement (C3, C4) consumption in cardiopulmonary bypass, cardioplegia, and protamine administration. Ann. Thorac. Surg. 37: 229, 1984.

15. Vogt, W. Factors in cobra venoms affecting the complement system. Toxicon 20: 299, 1982.

16. Smith, C. A., Vogel, C. W., and Muller-Eberhard, H. J. Ultrastructure of cobra venom factor-depen- 
dent C3/C5 convertase and its zymogen, factor $B$ of human complement. J. Biol. Chem. 257: 9879, 1982.

17. Zabern, I. V., Przyklenk, H., Damerau, B., and Zimmermann, B. Isolation and properties of complement inhibitor from Naja haje venom, distinct from known anticomplementary factors in cobra venom. Scand. J. Immunol. 14: 109, 1981.

18. Wakefield, T. W., Bouffard, J. A., Spaulding, S. A., Petry, N. A., Gross, M. D., Lindblad, B., and Stanley, J. C. Sequestration of platelets in the pulmonary circulation as a consequence of protamine reversal of the anticoagulant effects of heparin. J. Vasc. Surg. 1: $187,1987$.

19. Lindblad, B., Wakefield, T. W., Whitehouse, W. M., Jr., and Stanley, J. C. The effect of protamine sulfate on platelet function. Scand. J. Thorac. Cardiovasc. Surg., in press.

20. Radegran, K., Taylor, G. A., and Olsson, P. Mode of action of protamine in regard to its circulatory and respiratory side effects. Eur. Surg. Res. 3: 139, 1971.

21. Cobel-Geard, R. J., and Hassouna, H. I. Interaction of protamine sulfate with thrombin. Amer. J. Hematol. 14: 227, 1983.

22. Okajima, Y., Kanayama, S., Maeda, Y., Urano, S., Kitani, T., Watada, M., Nakagawa, M., and Ijichi, $H$. Studies on the neutralizing mechanism on antithrombin activity of heparin by protamine. Thromb. Res. 24: 21, 1981.

23. William, B. D. The complement system. Brit. $J$. Anaesth. 51: 7, 1979. 